\title{
Validation of ASTER Surface Temperature Data with In Situ Measurements to Evaluate Heat Islands in Complex Urban Areas
}

\author{
Bonggeun Song and Kyunghun Park \\ Department of Environmental Engineering, Changwon National University, 20 Changwondaehak-ro Uichang-gu Changwon-si, \\ Gyeongsangnam-do 641-773, Republic of Korea \\ Correspondence should be addressed to Kyunghun Park; landpkh@changwon.ac.kr
}

Received 27 August 2013; Accepted 6 December 2013; Published 20 January 2014

Academic Editor: Yuriy Kuleshov

Copyright (C) 2014 B. Song and K. Park. This is an open access article distributed under the Creative Commons Attribution License, which permits unrestricted use, distribution, and reproduction in any medium, provided the original work is properly cited.

\begin{abstract}
This study compared Advanced Spaceborne Thermal Emission Reflection Radiometer (ASTER) surface temperature data with in situ measurements to validate the use of ASTER data for studying heat islands in urban settings with complex spatial characteristics. Eight sites in Changwon, Korea, were selected for analyses. Surface temperature data were extracted from the thermal infrared (TIR) band of ASTER on four dates during the summer and fall of 2012, and corresponding in situ measurements of temperature were also collected. Comparisons showed that ASTER derived temperatures were generally $4.27^{\circ} \mathrm{C}$ lower than temperatures collected by in situ measurements during the daytime, except on cloudy days. However, ASTER temperatures were higher by $2.23-2.69^{\circ} \mathrm{C}$ on two dates during the nighttime. Temperature differences between a city park and a paved area were insignificant. Differences between ASTER derived temperatures and onsite measurements are caused by a variety of factors including the application of emissivity values that do not consider the complex spatial characteristics of urban areas. Therefore, to improve the accuracy of surface temperatures extracted from infrared satellite imagery, we propose a revised model whereby temperature data is obtained from ASTER and emissivity values for various land covers are extracted based on in situ measurements.
\end{abstract}

\section{Introduction}

Cities all over the world are experiencing more common urban heat islands (UHIs), whereby urban settlements are hotter than rural areas because of the rapid increase in artificial land cover such as asphalt [1-4]. Urban heat islands can generate tropical nighttime conditions and exacerbate heat waves, which negatively affects the health and welfare of urban residents [5-8]. Moreover, temperature increases from UHIs greatly increase energy consumption from the use of coolers $[9,10]$ and the aggregated effects from UHIs can cause changes in urban ecosystems [11]. The problems associated with UHIs are expected to worsen with global warming and UHIs are rapidly expanding into a global environmental issue of concern [12-14].

To alleviate adverse effects from UHIs, a wide range of studies have been performed using data on land surface temperatures (LSTs) extracted from remotely sensed thermal infrared data [15-18]. Surface temperature data derived from satellite images can be used to assess characteristics of UHIs such as how temperatures vary across the canopy layer of roofs and other surface features [19-23] or how temperatures are related to the surface energy balance [24-28]. In addition, satellite images of surface temperature data can supplement in situ temperature measurements collected by meteorological networks. Thus, satellite data can be used to analyze the general features of atmospheric UHIs in urban areas $[29,30]$.

To use satellite image-based surface temperature data for heat island studies in urban areas with complex spatial characteristics, important factors that influence surface temperatures must be considered comprehensively [31, 32]; these factors include the coverage texture type, the color of the surface layer, sky view factors, street geometry, traffic loads, and other anthropogenic activities. It is also important to validate the accuracy of satellite image surface temperature data by comparing it to in situ surface temperature data. Such analyses are necessary to diagnose UHIs more accurately and prepare appropriate relief plans.

Several recent studies have been conducted to validate or improve the accuracy of satellite temperature measurements by comparing satellite image surface temperature 
data to temperatures measured onsite. Mihalcea et al. [33] compared surface temperatures from onsite measurements and Advanced Spaceborne Thermal Emission Reflection Radiometer (ASTER) video images according to supraglacial debris coating and depth. Rigo et al. [34] validated the effectiveness of thermal infrared satellite images by comparing the earth radiation energy extracted from the images to data collected from eight fixed weather stations that were installed in urban, suburban, and rural areas of Basel, Switzerland. Nichol et al. [35] attempted to investigate UHIs and validate the accuracy of ASTER image surface temperature data by measuring surface temperatures at 18 sites located throughout the urban region of Kowloon in Hong Kong and the nonurban area of the New Territories in Hong Kong. In Scottsdale, Arizona, which is located in the Phoenix Metropolitan Area, Hartz et al. [36] classified land cover into asphalt, concrete, roof, and plant life and measured the surface temperature of each material using a thermal infrared camera. Then, the results were compared to surface temperatures derived from ASTER video images. All of these studies found that satellite temperature data were useful as surrogate measures for in situ temperature data.

Nonetheless, most relevant studies to date that compare in situ temperature data to satellite-based measurements are limited to homogeneous areas or rural areas. In addition, studies that have analyzed UHIs in urban areas with complex spatial characteristics are limited by their use of low resolution satellite images. Therefore, this study aimed to validate the accuracy of satellite image surface temperature data in an urban area through comparisons of relatively high resolution ASTER video data to onsite temperature measurements. Analyses were conducted in the urban area of Changwon, Gyeongsangnam-do, Korea, which is going through rapid urbanization and has various land use and coverage characteristics. Additionally, we evaluated and compared temperature measurements collected during the day and the night because thermal characteristics can vary diurnally.

\section{Materials and Methods}

2.1. Experiment Site. The urban area of Changwon, Gyeongsangnam-do, Korea $\left(35^{\circ} 14^{\prime} 01.02^{\prime \prime} \mathrm{N}, 128^{\circ} 41^{\prime} 19.95^{\prime \prime} \mathrm{E}\right)$, has a population of approximately 500,000 people. The area is $125.91 \mathrm{~km}^{2}$ wide, and it is located in a basin surrounded by mountains that are approximately $600 \mathrm{~m}$ in height. The city, in which residential, commercial, and business areas are concentrated, contains a large floating population (i.e., nonresidential population) and dense traffic. Its annual average temperature is $15^{\circ} \mathrm{C}$, and the annual precipitation is $1,396 \mathrm{~mm}$ [37].

The experiment site was established as the first planned city in Korea [38]. The site contains clear divisions of residential, commercial, and industrial quarters. It is composed of various structural patterns and coverage materials such as asphalt, concrete, greenery, sidewalk bricks, and tiles. In this study, we selected a total of eight sites for analyses, including a university campus, an urban park, a commercial area, lowrise apartments, high-rise apartments, a single residential area, an open lawn square of homogeneous coverage material, and a sidewalk brick square (Figure 1). These sites were selected because of their diverse land use and coverage characteristics, and in situ measurements at these sites were compared to data from satellite images.

\subsection{Setup of GIS Data and Satellite Imagery}

2.2.1. ASTER Video Data. Satellite image-based surface temperature data were extracted using the Level 2B03 Product (surface kinetic temperature) from the thermal infrared (TIR) band of ASTER. The ASTER instrument, located onboard the Terra satellite, is composed of three sensors: SWIR (short wave infrared), VNIR (visible near infrared), and TIR (thermal infrared). It also has 14 spectrum channels to analyze radiance. Among them, the TIR generates products between channels 10 and $14(8.15-11.65 \mu \mathrm{m})$ [39]. The spatial resolution of the ASTER 2B03 product is $90 \mathrm{~m}$, and it is used to generate data for the Temperature Emissivity Separation (TES) algorithm used for determining the emissivity of land coverage values $[36,40]$.

This study collected four ASTER video images on almost cloudless, sunny days between June and September 2012. In particular, the acquisition times were at 02:10 pm UTC on July 28, 2012 (daytime), 01:31 am UTC on September 21, 2012 (nighttime), 02:16 pm UTC on September 23, 2012 (daytime), and 01:37 am UTC on September 28, 2012 (nighttime). Surface temperatures were extracted after geometric corrections and coordinate transformations had been performed using the Geodetic Reference System (GRS) 80 equipped with PGSTEAMER version 4.2 (Pixoneer Corp.) software, an image processing program.

2.2.2. Urban Characteristics Data. Surface fabric classification of the eight subject areas was performed through onsite investigations and the use of $10 \mathrm{~cm}$ high spatial resolution aerial photograph orthoimagery and land coverage maps from the Changwon Environment Atlas. The land coverage maps in the Changwon Environment Atlas are composed of very detailed GIS spatial data that contain 31 coverage properties such as structures, asphalt, concrete, trees, and bare lands at a 1:1,000 scale [41]. The reserve surface fabrics were selected after considering the unclassified fabrics based on the land coverage maps. A total of 21 surface fabrics, identifiable on the maps when compared to the aerial photograph, were ultimately selected.

Temperatures may vary in areas with the same surface fabric because trees and buildings will form shadows during the daytime that alter the amount of radiant energy flowing into the surface [42]. Thus, shaded areas during the daytime of July 28th and September 23rd were classified as surface fabrics and reflected in the analyses. Analyses were performed through use of the Hillshade function of the ArcGIS 9.3 program using digital terrain models (DTM) extracted from light interferometry detection and ranging (LiDAR) images with a $1 \mathrm{~m}$ spatial resolution. The input variables of sun altitude and azimuth were matched to the times of the video collection. The values used were as follows: $63^{\circ} 52^{\prime} 51.60^{\prime \prime}$ and $188^{\circ} 31^{\prime} 40.10^{\prime \prime}$ for the July 28 and $44^{\circ} 17^{\prime} 04.40^{\prime \prime}$ and 

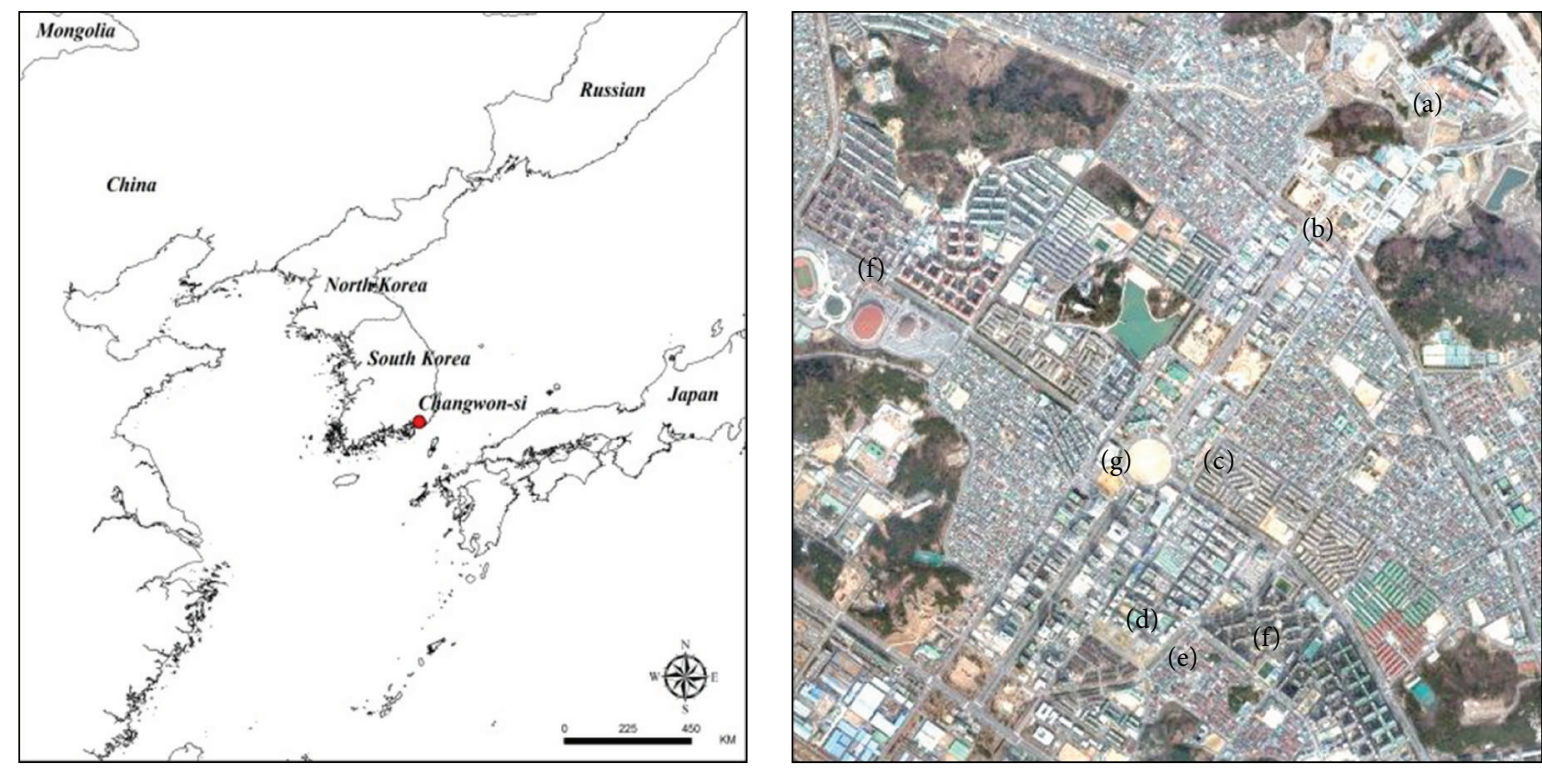

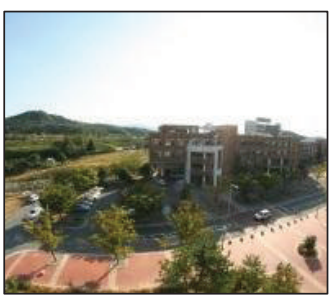

(a)

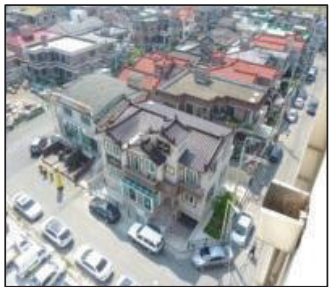

(e)

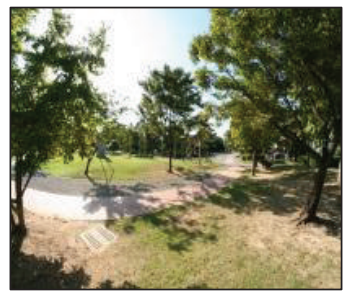

(b)

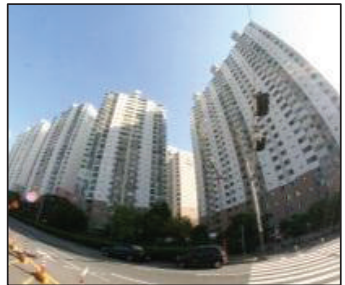

(f)

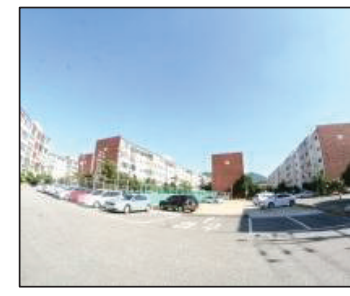

(c)

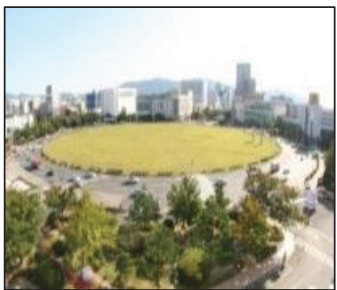

(g)

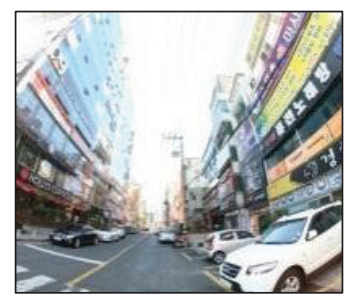

(d)

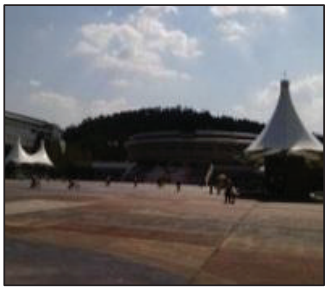

(h)

FIGURE 1: The experiment site and the eight measurement sites in the urban area of Changwon, Republic of Korea. (a) University campus, (b) urban park, (c) low-rise apartments, (d) commercial area, (e) single residential, (f) high-rise apartments, (g) lawn square, and (h) sidewalk brick square.

$220^{\circ} 47^{\prime} 57.60^{\prime \prime}$ for the September 23. Because the inflow of radiant energy was blocked in shaded areas, the surface temperatures in these regions were almost equivalent to air temperatures; hence, site temperatures measurements were substituted as surface temperatures at some locations [43].

\subsection{In Situ Measurement Data and Methods}

2.3.1. Measurements of Surface Temperature and Weather Variables. By considering the composition ratio of the surface fabric and measurement times at each subject site, a total of 366 points were chosen from the 8 sites for analyses (78 places in the university campus, 64 in the park, 53 in the low-rise apartments, 63 in the commercial area, 41 in the single residential area, 55 in the high-rise apartments, 6 from the lawn square, and 6 from the sidewalk bricks) (Figure 2). Onsite measurements were carried out for approximately an hour at each site (daytime: 14:00 - 15:00 and nighttime: 01:00 - 02:00). The measurements were collected so that the data would span 30 minutes before and after the time in which the satellite took pictures.

Temperatures were measured using thermal infrared thermometers that were held $10 \mathrm{~cm}$ vertically off the surface. A portable Kestrel 4500 Weather Meter was also used to measure weather related variables such as temperature, relative humidity, and wind speed at each measuring point (air temperature accuracy: $\pm 1.0^{\circ} \mathrm{C}$, wind speed accuracy: $\pm 3 \%$, and relative humidity $(\mathrm{RH})$ accuracy: $\pm 3 \%)$.

To account for changes in the surface temperature according to the elapsed site measurement time, we attempted to 


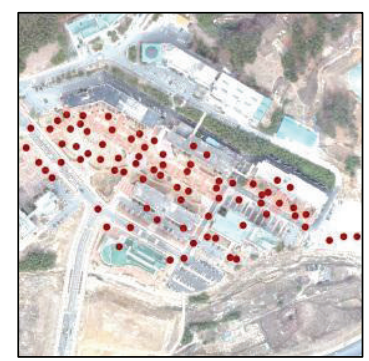

(a)

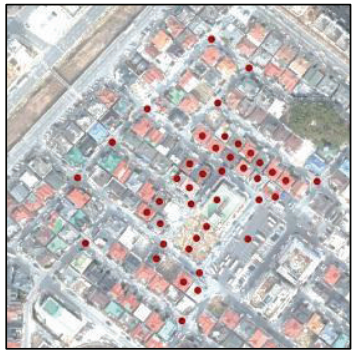

(e)

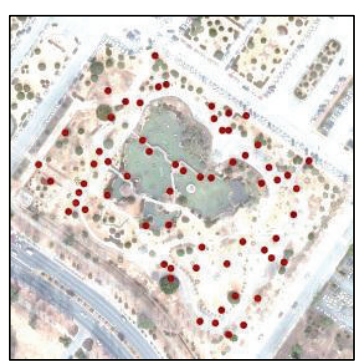

(b)

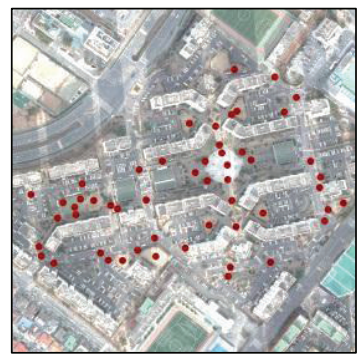

(f)

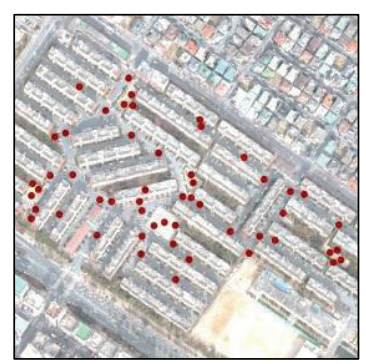

(c)

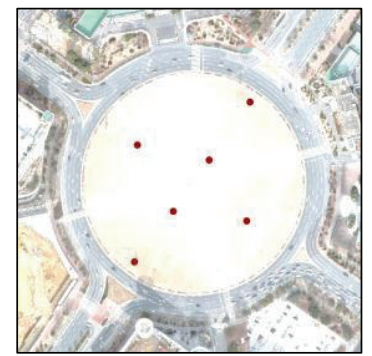

(g)

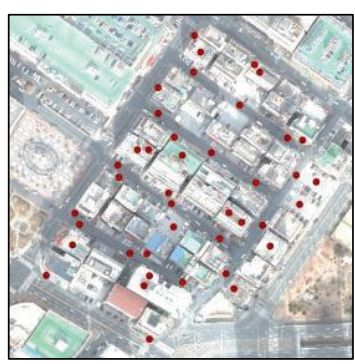

(d)

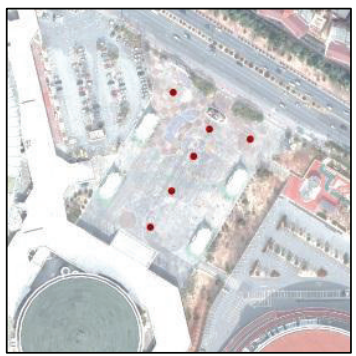

(h)

FIGURE 2: Surface temperature measurement points within the eight subject sites. (a) University campus (78 points), (b) urban park (64 points), (c) low-rise apartments (53 points), (d) commercial area (63 points), (e) single residential (41 points), (f) high-rise apartments (55 points), (g) lawn square (6 points), and (h) sidewalk brick square (6 points).

TABLe 1: Area ratio and division of sunny and shaded areas per location per date.

\begin{tabular}{lcccccccc}
\hline \multirow{2}{*}{ Date } & \multicolumn{10}{c}{ Site } \\
& UC & P & LR & CA & SR & HR & LS & SS \\
\hline 28 July 2012 & & & & & & & & \\
$\quad$ Sunny (\%) & 98.7 & 90.2 & 81.2 & 76.1 & 85.3 & 67.5 & 96.6 & 89.6 \\
$\quad$ Shade (\%) & 10.4 & 9.8 & 18.8 & 24.0 & 14.7 & 32.5 & 3.4 & 10.4 \\
23 September 2012 & & & & & & & & \\
$\quad \begin{array}{l}\text { Sunny (\%) } \\
\text { Shade (\%) }\end{array}$ & 82.7 & 81.9 & 67.8 & 63.5 & 77.1 & 55.7 & 92.6 & 83.3 \\
\hline
\end{tabular}

UC: university campus, P: urban park, LR: low-rise apartments, CA: commercial area, SR: single residential, HR: high-rise apartments, LS: lawn square, and SS: sidewalk brick square.

perform a correction through the use of linear regression techniques. However, the temperature differences over time were below $0.5^{\circ} \mathrm{C}$; hence, the data were not corrected for time differences. Furthermore, we were limited in our ability to perform measurements on top of single residential buildings; hence, roof temperatures in these areas were measured using thermal imaging cameras (temperature accuracy: $\pm 2^{\circ} \mathrm{C}$ ) from the roofs of nearby high-rise business buildings.

2.3.2. Emissivity Calculation Method. Emissivity refers to the ability of a surface fabric to absorb, transmit, and reflect external radiant energy. Emissivity values are rated against a black body, which theoretically will only absorb energy without reflecting it [44].
Surface temperature data extracted from the satellite image represents radiant temperature, which is the temperature conversion of radiant energy released from the surface, and it is closely related to the emissivity for surface fabrics [33, 45]. Valor and Caselles [46] and Caselles et al. [47] stated, "retrieval of LST from TIR data requires an accurate measurement of emissivity values of the surface." Therefore, it is necessary to compare it to actual measurements of emissivity from various surface fabrics of the urban area.

Emissivity was calculated using the Stefan-Boltzmann law as follows:

$$
\varepsilon_{i}=\frac{L_{i}}{\varepsilon_{0.95} \times \sigma \times\left(273.15+T_{s i}\right)^{4}} .
$$

Here, $\varepsilon_{i}$ is the emissivity of fabric $i, L_{i}$ is the earth radiant energy of fabric $i$ measured by the CNR4 netradiometer, $\varepsilon_{0.95}$ is the set emissivity of the thermal infrared thermometer (0.95), $T_{s i}$ is the surface temperature of the fabric $i$ using a thermal infrared thermometer, and $\sigma$ is the Stefan-Boltzmann constant $\left(5.67 \times 10^{-8} \mathrm{~W} \mathrm{~m}^{-2} \mathrm{~K}^{-4}\right)$.

Emissivity for each surface fabric was calculated after measuring the surface temperature and radiant energy of the 21 surface fabrics classified in the city characteristic data (Table 2). Radiant energy was measured using a CNR4 netradiometer (Kipp and Zonen Inc.) by holding it horizontally approximately $10 \mathrm{~cm}$ away from the surface for a minute to two. The surface temperature was measured by holding a thermal infrared thermometer (Testo 381 model, accuracy: $\pm 1.5^{\circ} \mathrm{C}$, emissivity: 0.95$) 10 \mathrm{~cm}$ perpendicular to the surface.

Measurements were performed during 10:00 to 16:00 on three days, May 27, June 5, and June 24, which consisted 
TABLE 2: Surface temperature and emissivity of different surface fabrics measured onsite. Surface temperatures that were measured in shaded areas during the day were excluded.

\begin{tabular}{|c|c|c|c|c|c|c|c|c|c|c|c|c|c|}
\hline \multirow{4}{*}{ Surface fabric } & \multirow{4}{*}{ Emissivity } & \multicolumn{12}{|c|}{ Surface temperature } \\
\hline & & \multicolumn{6}{|c|}{ Daytime } & \multicolumn{6}{|c|}{ Nighttime } \\
\hline & & \multicolumn{3}{|c|}{28 July 2012} & \multicolumn{3}{|c|}{23 September 2012} & \multicolumn{3}{|c|}{21 September 2012} & \multicolumn{3}{|c|}{28 September 2012} \\
\hline & & No. & Mean $\left({ }^{\circ} \mathrm{C}\right)$ & $\mathrm{SD}$ & No. & Mean $\left({ }^{\circ} \mathrm{C}\right)$ & SD & No. & Mean $\left({ }^{\circ} \mathrm{C}\right)$ & $\mathrm{SD}$ & No. & Mean $\left({ }^{\circ} \mathrm{C}\right)$ & SD \\
\hline Metal roof & 0.99 & 1 & 44.5 & - & 1 & 36.8 & - & 1 & 19.1 & - & 1 & 17.0 & - \\
\hline Roof tile (brown) & 0.98 & 12 & 55.9 & 5.2 & 7 & 47.7 & 4.0 & 12 & 15.6 & 0.6 & 12 & 13.6 & 1.7 \\
\hline Roof tile (black) & 0.99 & 6 & 57.4 & 7.0 & 6 & 46.9 & 5.1 & 6 & 15.6 & 1.8 & 6 & 15.0 & 1.3 \\
\hline Roof tile (green) & 0.99 & 1 & 51.7 & - & 1 & 41.5 & - & 1 & 17.9 & - & 1 & 16.9 & - \\
\hline Wooded board & 0.95 & 4 & 69.0 & 0.6 & 6 & 52.2 & 1.9 & 9 & 12.1 & 3.3 & 7 & 12.2 & 0.6 \\
\hline Sand and bare & 0.96 & 20 & 47.8 & 6.6 & 17 & 30.6 & 6.5 & 20 & 15.7 & 0.9 & 20 & 15.1 & 0.7 \\
\hline Sidewalk brick & 0.96 & 40 & 50.1 & 3.9 & 40 & 39.3 & 5.0 & 47 & 17.8 & 2.1 & 46 & 17.9 & 1.2 \\
\hline Water & 1.00 & 6 & 27.0 & 0.4 & 6 & 21.4 & 0.8 & 6 & 17.3 & 1.2 & 6 & 19.9 & 0.4 \\
\hline Tree and lawn & 0.97 & 67 & 37.7 & 3.3 & 88 & 28.4 & 4.1 & 92 & 14.2 & 2.1 & 91 & 15.3 & 1.2 \\
\hline Asphalt & 0.96 & 75 & 58.5 & 4.2 & 53 & 45.5 & 3.7 & 76 & 19.6 & 1.3 & 75 & 18.7 & 1.2 \\
\hline Green roof & 0.93 & 7 & 40.0 & 3.9 & 5 & 26.2 & 3.0 & 7 & 15.9 & 1.0 & 4 & 16.7 & 1.0 \\
\hline Urethane & 0.96 & 2 & 66.2 & 1.1 & 2 & 49.3 & 0.2 & 2 & 15.3 & 0.1 & 2 & 14.4 & 0.5 \\
\hline Artificial turf & 0.96 & 6 & 56.1 & 3.2 & 6 & 39.9 & 1.2 & 6 & 17.0 & 0.9 & 6 & 16.8 & 0.7 \\
\hline Gravel & 0.98 & 14 & 52.3 & 3.6 & 14 & 37.5 & 2.4 & 15 & 13.9 & 1.1 & 15 & 15.0 & 1.1 \\
\hline Concrete & 0.97 & 8 & 54.2 & 2.6 & 8 & 40.5 & 2.6 & 9 & 19.7 & 0.8 & 9 & 18.8 & 0.7 \\
\hline Concrete roof (green) & 0.98 & 7 & 57.4 & 2.4 & 4 & 43.0 & 3.5 & 5 & 18.1 & 1.2 & 5 & 18.0 & 0.6 \\
\hline Concrete roof (gray) & 0.98 & 16 & 58.7 & 2.7 & 13 & 43.7 & 4.1 & 15 & 19.9 & 2.2 & 15 & 18.4 & 1.8 \\
\hline Tile & 1.00 & 5 & 48.7 & 7.0 & 6 & 30.5 & 4.1 & 6 & 19.6 & 1.0 & 6 & 17.7 & 0.4 \\
\hline Flagstone & 0.96 & 5 & 57.2 & 1.6 & 6 & 42.1 & 2.3 & 6 & 15.7 & 1.8 & 6 & 17.7 & 0.5 \\
\hline Granite & 0.98 & 1 & 48.0 & - & 1 & 41.3 & - & 1 & 21.4 & - & 1 & 19.3 & - \\
\hline Homogeneous lawn & - & 6 & 43.5 & 6.9 & 6 & 33.0 & 1.8 & 6 & 12.8 & 0.8 & 6 & 12.3 & 0.5 \\
\hline Homogeneous sidewalk brick & - & 6 & 62.0 & 1.1 & 6 & 46.2 & 0.8 & 6 & 15.3 & 0.5 & 6 & 19.3 & 0.8 \\
\hline
\end{tabular}

of clear weather. Measurement points were selected with the composition ratio of surface fabric per subject area in mind and measurements were collected in spots that were as homogeneous as possible (i.e., not mixed with other fabric types).

\subsection{Comparison Method for ASTER and In Situ Measurements} of Surface Temperature. Direct comparisons between the surface temperatures of satellite derived pixel images and geographically identical pixel locations were performed for ASTER image data and onsite measurements. To do so, the entire field measurement site was divided into Vector GRIDs of $90 \mathrm{~m} \times 90 \mathrm{~m}$, which was identical to the spatial resolution of the ASTER image (Figure 3).

For the field measured surface temperatures, the mean surface temperature of each GRID was calculated after analyzing the area ratio per surface fabric per GRID according to the following equation:

$$
T_{s}=\sum_{i=1}^{n}\left[\left\{\sqrt[4]{\frac{0.95}{\varepsilon_{i}}\left(273.15+T_{s i}\right)^{4}}-273.15\right\} \times A_{i}\right] \text {. }
$$

Here, $T_{s}$ is the mean surface temperature per GRID, $\varepsilon_{i}$ is the emissivity of fabric $i, T_{s i}$ is the surface temperature of fabric $i$, and $A_{i}$ is the area ratio of the fabric $i$.
The mean surface temperature calculated for each GRID was compared to the surface temperature of the exact location on the ASTER image. The difference in the surface temperature between the satellite image and the field measurement was contemplated in connection with the spatial characteristics of the subject area and the pixels.

\section{Results and Discussion}

3.1. Spatial Patterns of ASTER Surface Temperature. Figure 4 shows the surface temperature results that were extracted from the ASTER images. Surface temperature was high during the day mostly in places covered with concrete and asphalt. Although the commercial area, low-rise apartments, and high-rise apartments had higher surface temperatures during the night compared to the daytime, the differences were insignificant. According to the image taken on July 28, portions of the commercial area, high-rise apartments, and single residential area had low surface temperatures due to the influence of clouds.

Among the mean surface temperatures at each of the 8 sites, the block square $\left(07 / 28: 44.3^{\circ} \mathrm{C}, 09 / 23: 33.2^{\circ} \mathrm{C}\right)$ had the highest temperature during the day, and the commercial area (09/21: $\left.19.4^{\circ} \mathrm{C}, 09 / 28: 19.0^{\circ} \mathrm{C}\right)$ and the high-rise apartments (09/21: $18.7^{\circ} \mathrm{C}, 09 / 28: 19.2^{\circ} \mathrm{C}$ ) had the highest temperatures during the night (Table 3 ). 


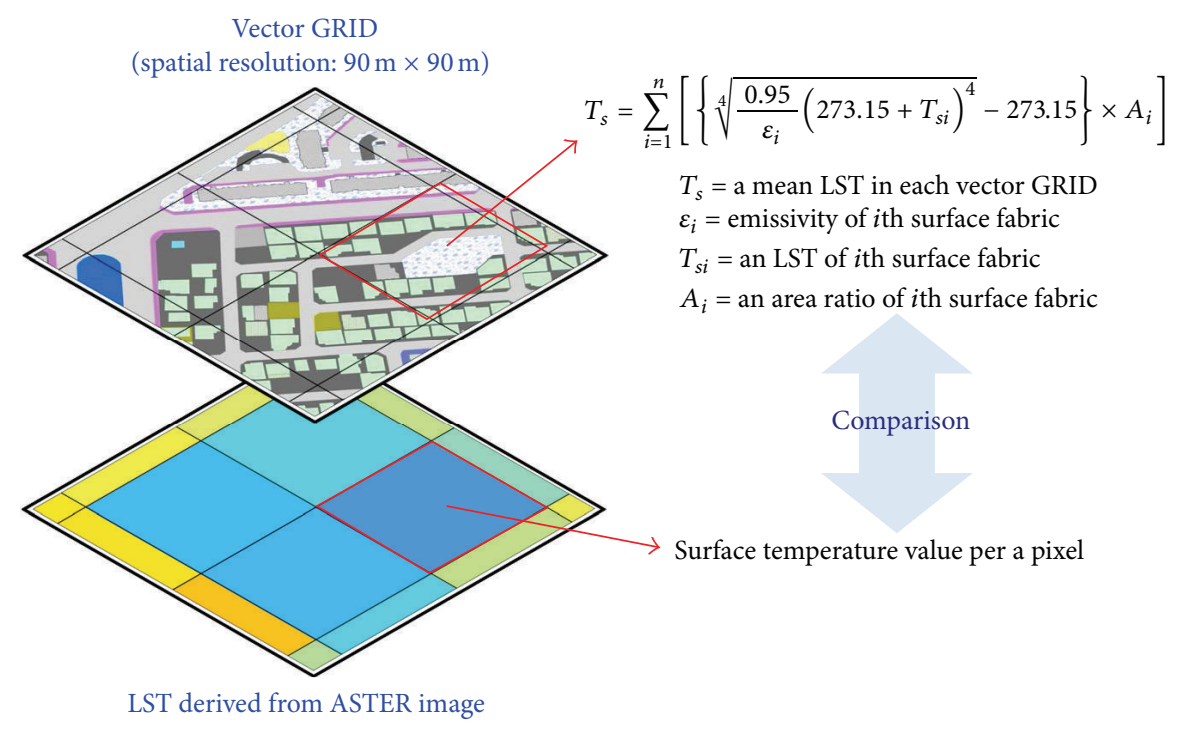

FIGURE 3: Surface temperature comparison of values collected by ASTER images and field measurements.

\subsection{Classification of Surface Fabric and Shaded Areas per} Location. Figure 5 shows the classification of surface fabric. The university campus was mostly composed of asphalt, sidewalk bricks, trees, and grass. Low-rise apartments and commercial areas were mostly composed of concrete on the building roofs (grey) and asphalt. Single residential areas had a high amount of asphalt and tiled roofs of various colors. High-rise apartments were composed of various fabrics such as asphalt, concrete (grey) sidewalk bricks, trees, grass, and tile. Asphalt was common in the areas around homogeneous lawn squares and sidewalk brick plazas.

Analyses of the shaded areas created by buildings and other structures were limited to the date the satellite photography and field measurements took place. As the altitude of the sun was higher and the azimuth was smaller on July 28 than on September 23, the amount of shaded area was smaller. The commercial area and the high-rise apartment area, which were packed with tall buildings, had a high percentage of shaded areas (Figure 6), while the lawn square area was the least affected by the shade because of its location in an open space (Table 1).

3.3. Emissivity and Surface Temperature by Field Measurements. Of the 21 types of surface fabrics, water and tile had the highest emissivity of 1.00, while the green roof system had the lowest at 0.93 , according to measurement results of the emissivity per surface fabric (Table 2). The results of Sobrino et al. [45] demonstrated an emissivity of 0.985 for water surfaces, 0.990 for trees, 0.914 for concrete, 0.965 for asphalt, 0.902 for sidewalk bricks, 0.898 for bright bare soil, 0.970 for dark bare soil, and 0.897 for rooftops. These values were obtained by mapping emissivity per land coverage with ASTER images, and the values were somewhat different from those that were obtained during measurements in this study. Emissivity was especially different for artificial surface textures such as concrete, sidewalk bricks, and rooftops.
Field measurements of surface temperatures showed that temperatures were higher on September 23 than on July 28 by approximately $10^{\circ} \mathrm{C}$ on average. Wooden boards had the highest surface temperature $\left(07 / 28: 69.0^{\circ} \mathrm{C}, 09 / 23: 52.2^{\circ} \mathrm{C}\right)$, followed by urethane $\left(07 / 28: 66.2^{\circ} \mathrm{C}, 09 / 23: 49.3^{\circ} \mathrm{C}\right)$. Water had the lowest surface temperature $\left(07 / 28: 27.0^{\circ} \mathrm{C}, 09 / 23\right.$ : $\left.21.4^{\circ} \mathrm{C}\right)$. More open areas such as sidewalk brick squares (07/28: $\left.62.0^{\circ} \mathrm{C}, 09 / 23: 46.2^{\circ} \mathrm{C}\right)$ and lawn squares $(07 / 28$ : $43.5^{\circ} \mathrm{C}, 09 / 23: 33.0^{\circ} \mathrm{C}$ ) had higher surface temperatures than areas that were not open spatially (Table 2 ). This was likely caused by more continuous short wave radiation flowing into open areas.

Nighttime measurements showed little differences in surface temperatures between the different surface fabrics. In general, however, artificial fabrics such as asphalt (09/21: 19.6 $\left.{ }^{\circ} \mathrm{C}, 09 / 28: 18.7^{\circ} \mathrm{C}\right)$, concrete $\left(09 / 21: 19.7^{\circ} \mathrm{C}, 09 / 28: 18.8^{\circ} \mathrm{C}\right)$, and granite $\left(09 / 21: 21.4^{\circ} \mathrm{C}, 09 / 28: 19.3^{\circ} \mathrm{C}\right)$ had relatively higher surface temperatures. Extraordinarily, wooden boards, which had the highest surface temperature during the day, had the lowest temperature during the night $\left(09 / 21\right.$ : $12.1^{\circ} \mathrm{C}, 09 / 28$ : $12.2^{\circ} \mathrm{C}$ ) and water surfaces, which had the lowest temperature during the day, had the highest temperature during the night (09/21: $17.3^{\circ} \mathrm{C}, 09 / 28: 19.9^{\circ} \mathrm{C}$ ) (Table 2). This is because water has a large heat capacity. Thus, when water is subjected to external heat energy, the temperature rises and falls slowly and it can be relatively high during the night $[48,49]$. Open areas such as lawn squares $\left(09 / 21: 12.8^{\circ} \mathrm{C}, 09 / 28: 12.3^{\circ} \mathrm{C}\right)$ had lower surface temperatures than lawns that were not as open (09/21: $\left.13.4^{\circ} \mathrm{C}, 09 / 28: 14.6^{\circ} \mathrm{C}\right)$. This is because more compact spaces release less terrestrial radiation energy from the earth to the atmosphere, which leads to a greater aggregation of energy at the surface $[18,50]$. Temperatures reached $35.8^{\circ} \mathrm{C}$ on July $28,20.2^{\circ} \mathrm{C}$ on September $21,27.7^{\circ} \mathrm{C}$ on September 23 , and $20.7^{\circ} \mathrm{C}$ on September 28.

Surface temperatures calculated for each GRID using field measurement data showed that sidewalk brick squares 


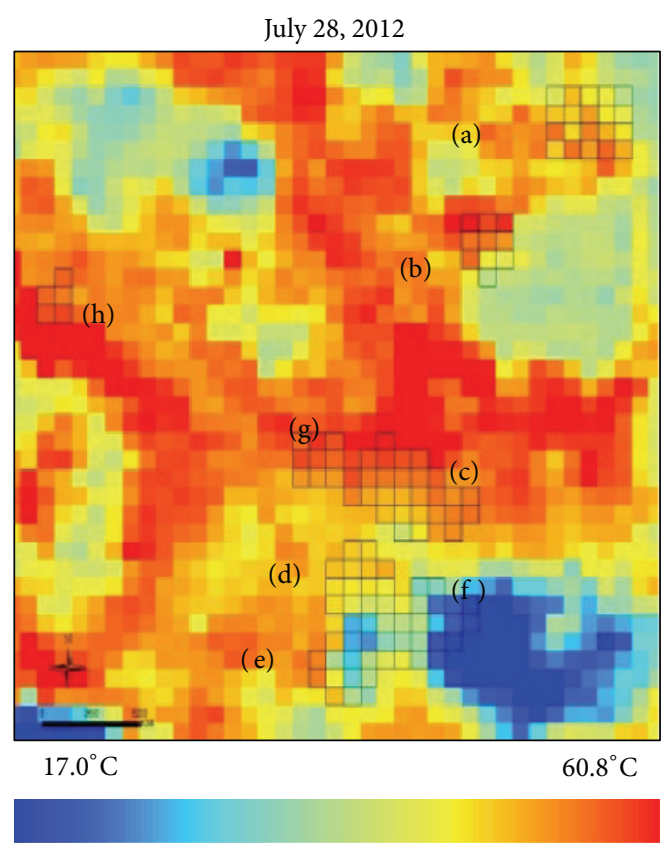

(a)

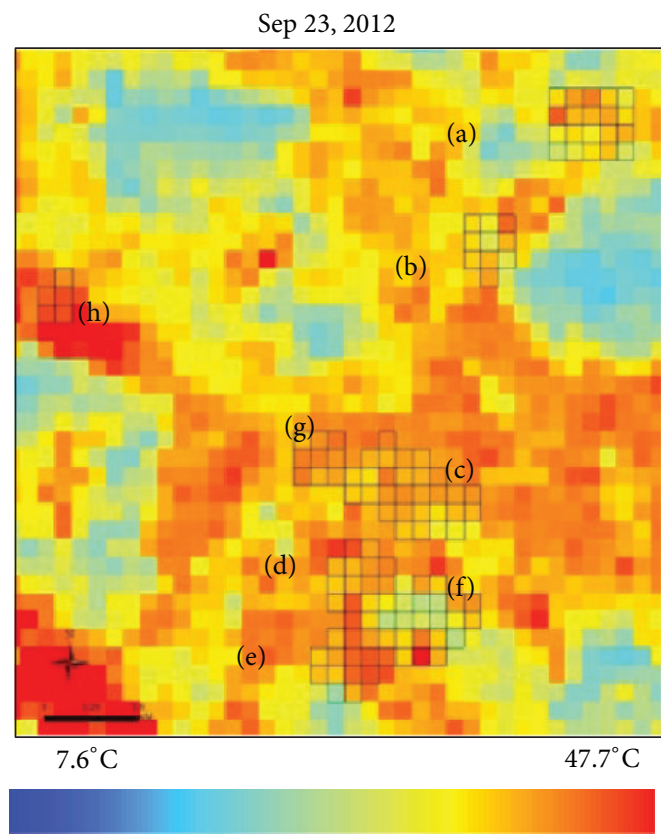

(c)

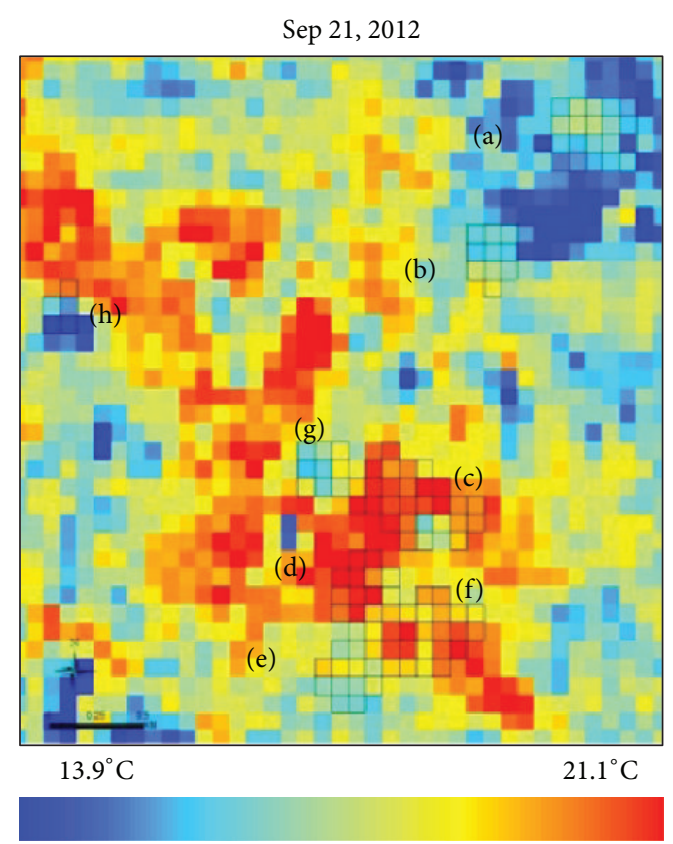

(b)

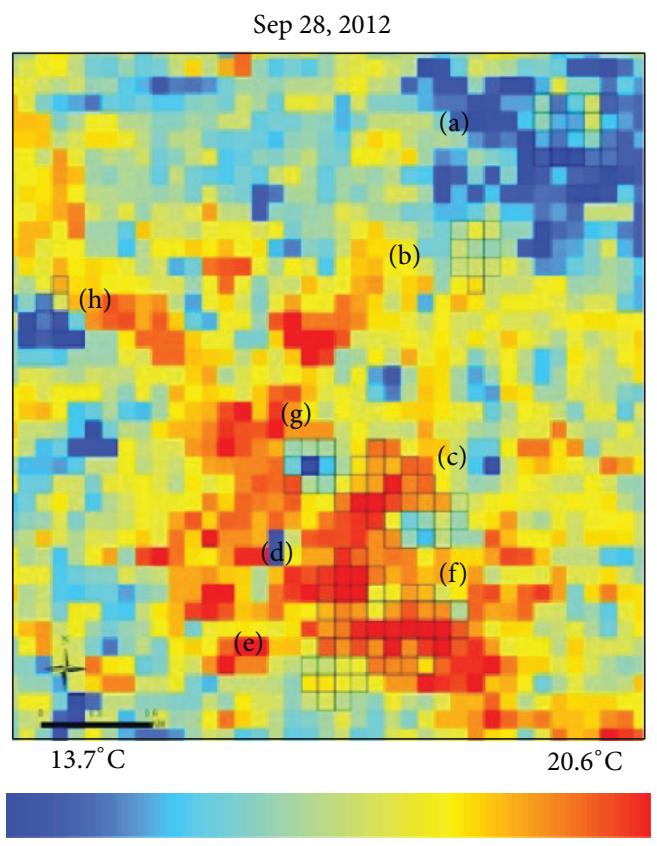

(d)

FIGURE 4: Surface temperatures extracted from ASTER images. (a) University campus, (b) urban park, (c) low-rise apartments, (d) commercial area, (e) high-rise apartments, (f) single residential, (g) lawn square, and (h) sidewalk brick square.

had the highest surface temperature during daytime (07/28: 51. $0^{\circ} \mathrm{C}, 09 / 23: 38.2^{\circ} \mathrm{C}$ ), and this was also demonstrated in the ASTER image. Although high-rise apartments had high amounts of asphalt, which typically have a high surface temperature, these areas had relatively low surface temperatures because they were affected by shade (07/28: $32.5 \%, 09 / 23$ : $44.3 \%$ ) (Table 1). The highest nighttime surface temperatures were measured in situ in the commercial area $\left(17.3^{\circ} \mathrm{C}\right)$ on September 21 and the sidewalk brick square area $\left(16.9^{\circ} \mathrm{C}\right)$ on September 28. In contrast, lawn squares had the lowest nighttime surface temperatures $\left(09 / 21: 14.3^{\circ} \mathrm{C}, 09 / 28: 13.9^{\circ} \mathrm{C}\right)$ (Table 3).

\subsection{Comparisons of ASTER Image and Field Measured Surface} Temperatures. Figure 7 shows a graph of the surface temperature difference between the field-based measurements and the satellite-based measurements for each pixel of the subject sites. Surface temperatures derived from ASTER 
TABLE 3: Comparison of mean surface temperatures collected from ASTER images and field measurements at the measurement sites.

\begin{tabular}{|c|c|c|c|c|c|c|c|c|c|}
\hline & & UC & $\mathrm{P}$ & LR & $\mathrm{CA}$ & SR & $\mathrm{HR}$ & $\mathrm{HL}$ & $\mathrm{HS}$ \\
\hline \multirow{8}{*}{ Daytime } & $07 / 28$ & & & & & & & & \\
\hline & $\mathrm{T}_{\text {image }}\left({ }^{\circ} \mathrm{C}\right)$ & 38.9 & 41.2 & 39.9 & 38.2 & 37.3 & 31.9 & 41.2 & 44.3 \\
\hline & $\mathrm{T}_{\text {insitu }}\left({ }^{\circ} \mathrm{C}\right)$ & 46.5 & 44.5 & 47.9 & 49.8 & 49.6 & 46.8 & 46.7 & 51.0 \\
\hline & $\operatorname{RMSE}\left({ }^{\circ} \mathrm{C}\right)$ & 8.1 & 5.4 & 8.4 & 11.8 & 13.4 & 15.7 & 6.1 & 7.9 \\
\hline & $09 / 23$ & & & & & & & & \\
\hline & $\mathrm{T}_{\text {image }}\left({ }^{\circ} \mathrm{C}\right)$ & 30.4 & 30.4 & 31.5 & 32.1 & 32.2 & 29.8 & 32.0 & 33.2 \\
\hline & $\mathrm{T}_{\text {insitu }}\left({ }^{\circ} \mathrm{C}\right)$ & 33.1 & 34.6 & 34.7 & 35.6 & 36.8 & 34.3 & 35.4 & 38.2 \\
\hline & RMSE $\left({ }^{\circ} \mathrm{C}\right)$ & 3.2 & 5.1 & 3.7 & 3.8 & 5.0 & 4.7 & 4.4 & 5.3 \\
\hline \multirow{8}{*}{ Nighttime } & $09 / 21$ & & & & & & & & \\
\hline & $\mathrm{T}_{\text {image }}\left({ }^{\circ} \mathrm{C}\right)$ & 17.0 & 17.3 & 19.0 & 19.4 & 17.7 & 18.7 & 17.6 & 17.3 \\
\hline & $\mathrm{T}_{\text {insitu }}\left({ }^{\circ} \mathrm{C}\right)$ & 15.3 & 15.3 & 16.5 & 17.3 & 16.4 & 16.4 & 14.3 & 16.0 \\
\hline & $\operatorname{RMSE}\left({ }^{\circ} \mathrm{C}\right)$ & 1.9 & 2.3 & 2.6 & 3.1 & 1.6 & 2.4 & 3.7 & 1.9 \\
\hline & $09 / 28$ & & & & & & & & \\
\hline & $\mathrm{T}_{\text {image }}\left({ }^{\circ} \mathrm{C}\right)$ & 16.5 & 17.8 & 18.7 & 19.0 & 18.5 & 19.2 & 17.3 & 17.3 \\
\hline & $\mathrm{T}_{\text {insitu }}\left({ }^{\circ} \mathrm{C}\right)$ & 15.0 & 15.5 & 16.1 & 16.5 & 15.8 & 16.0 & 13.9 & 16.9 \\
\hline & RMSE $\left({ }^{\circ} \mathrm{C}\right)$ & 1.6 & 2.4 & 2.7 & 2.5 & 2.8 & 3.3 & 3.9 & 1.1 \\
\hline
\end{tabular}

UC: university campus, P: urban park, LR: low-rise apartments, CA: commercial area, SR: single residential, HR: high-rise apartments, and HL: homogenous lawn, HS: homogenous sidewalk brick.

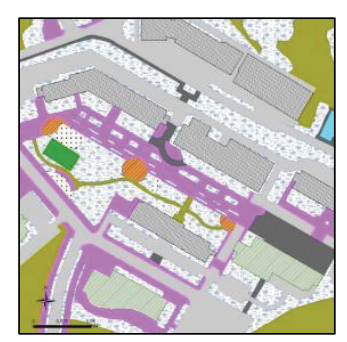

(a)

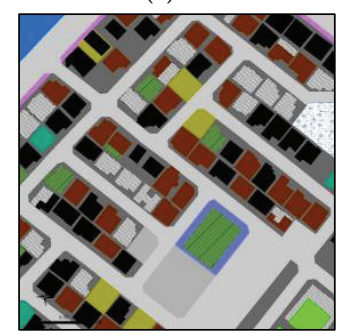

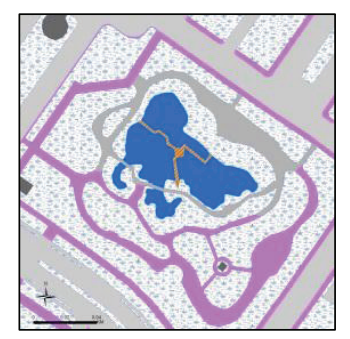

(b)

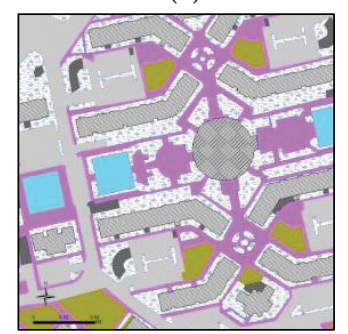

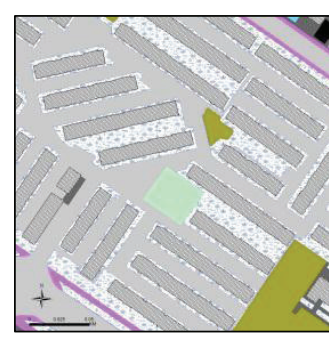

(c)

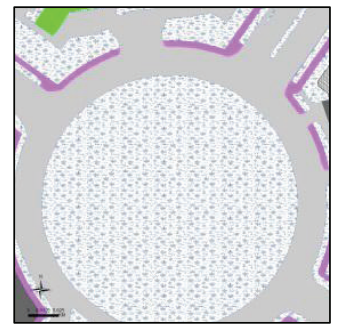

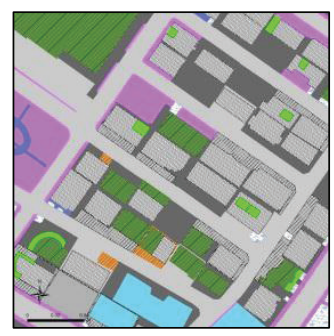

(d)
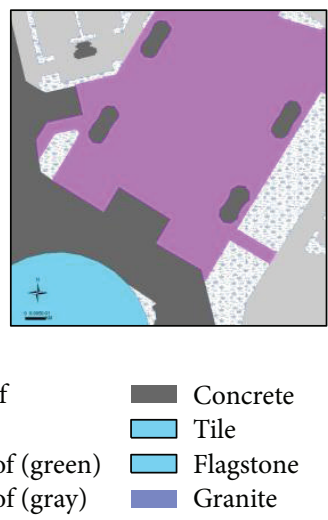

(h)

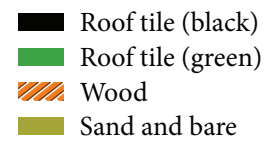

(f)

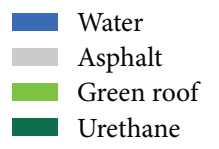

(g)

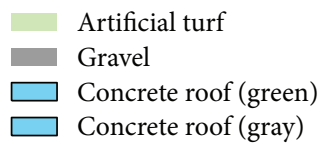

(g)

Figure 5: Classification of surface fabric for each location. (a) University campus, (b) urban park, (c) low-rise apartments, (d) commercial area, (e) single residential, (f) high-rise apartments, (g) lawn square, and (h) sidewalk brick square.

images differed greatly from those measured onsite (between 20 and $30^{\circ} \mathrm{C}$ ) in the commercial area and parts of the high-rise apartment area on July 28 because of the influence of clouds. Hence, the root mean square error (RMSE) was relatively high in these areas and it amounted to $10.73^{\circ} \mathrm{C}$. Satellite image surface temperatures of the water area in the park were $7.8^{\circ} \mathrm{C}$ higher than field measured temperatures. Except for a clouded area, the single residential area showed large differences in temperature; in contrast, adjacent vegetation covered areas showed very little differences in temperature 
July 28, 2012

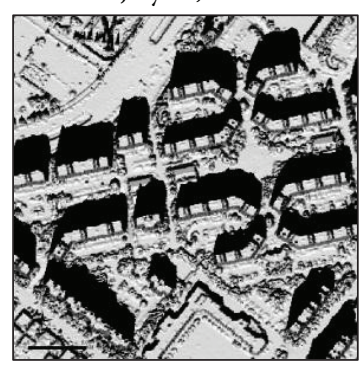

July 28, 2012

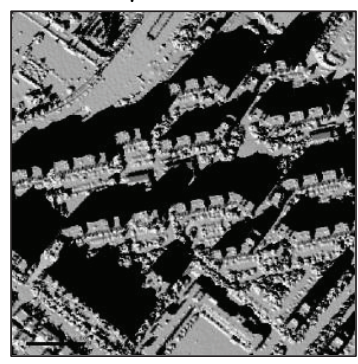

(a)
July 28, 2012

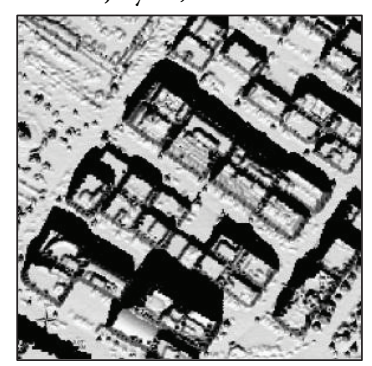

July 28, 2012

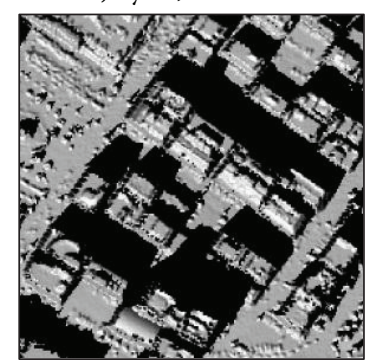

(b)

FIGURE 6: Shaded area analysis results for the high-rise apartments (a) and the commercial area (b).

that only amounted to $0.8^{\circ} \mathrm{C}$. In pixels composed of identical fabrics such as grass and sidewalk bricks, the differences were very small and amounted to $0.5^{\circ} \mathrm{C}$ and $0.4^{\circ} \mathrm{C}$, respectively. The park area had some of the lowest differences in temperature according to the RMSE (Table 3 ).

The RMSE was $2.23^{\circ} \mathrm{C}$ on September 21. The vegetation area pixel, which had the least difference in the single residential area data from July 28 , had the largest difference of $3.9^{\circ} \mathrm{C}$ on September 21. Pixels composed of identical grass fabric also demonstrated differences more than $5^{\circ} \mathrm{C}$, and the differences were the greatest for the data from September 21. Subject areas with small temperature variances included the single residential area $\left(1.6^{\circ} \mathrm{C}\right)$, the university campus $\left(1.9^{\circ} \mathrm{C}\right)$, and the sidewalk brick square $\left(1.9^{\circ} \mathrm{C}\right)$ (Table 3$)$.

Similar patterns were observed on September 23 and July 28. Surface temperatures from the satellite images of water in the park were higher than the field-measured surface temperatures by $1.7^{\circ} \mathrm{C}$. In the single residential area, the pixels with vegetation had the least difference $\left(0.1^{\circ} \mathrm{C}\right)$. Interestingly, in the homogeneous lawn pixels and the vegetation pixels in the university campus, the surface temperatures from the satellite images were higher than the field measured temperatures. The university campus $\left(3.2^{\circ} \mathrm{C}\right)$, low-rise apartment area $\left(3.7^{\circ} \mathrm{C}\right)$, and the commercial area $\left(3.8^{\circ} \mathrm{C}\right)$ had low RMSEs (Table 3).

On September 28th, similar to the nighttime of September 21st, the homogeneous lawn pixel had the greatest temperature differences range from $5.9^{\circ} \mathrm{C}$ to $6.4^{\circ} \mathrm{C}$. In the single residential area, however, and unlike the data observed on September 21st, other pixels along with the vegetation pixels displayed large temperature differences. Homogeneous sidewalk bricks had the lowest RMSE of $1.1^{\circ} \mathrm{C}$, followed by the university campus $\left(1.6^{\circ} \mathrm{C}\right)$ (Table 3 ).

Therefore, as the results of the comparisons described above show, the temperature data derived from satellite images has accuracy problems that vary according to land coverage and land use in the urban area. First, higher building densities are associated with larger differences between satellite-based and field-based temperature measurements. According to an earlier study by Hartz et al. [36], areas with greater population have greater temperature differences between ASTER image measurements and field measurements of surface temperatures. Barring et al. [51] and Eliasson [2] discovered that more densely built up areas had greater surface temperature differences of about $4 \sim 8^{\circ} \mathrm{C}$. Voogt and Oke [16] speculated that the limited horizontal surface view from ASTER was the cause of the discrepancy. Therefore, in a spatial structure with high density characteristics, the amount of radiation energy from the earth sensed by the satellite may be misjudged because of the limited horizontal surface view. For example, during the night denser areas (e.g., commercial areas, low-rise apartments, and high-rise apartments) had greater differences in temperature between satellite and field measurement data. This is believed to be because in areas packed with buildings, the radiation energy released from the earth into the atmosphere is blocked and aggregated in the earth $[18,50]$; and because satellites cannot sense this, it causes differences. Moreover, denser areas had greater differences in surface temperatures for the satellite imagery between the walls of the buildings, and not the temperature of the surface, and field measurements due to the off-nadir angle $\left(\right.$ ASTER $=22.5^{\circ}$ ) of the satellite image. Furthermore, there may be effects on the emissivity values used to extract the surface temperatures from the satellite images. According to Han et al. [52], "a 1\% change in emissivity can change the surface temperature up to $2 \mathrm{~K}$." Therefore, because satellite images have low spatial resolutions, they are limited in their ability to analyze exact and detailed emissivity values in urban areas composed of various surface fabrics, and the resulting data will show different surface temperatures from field measurements.

\section{Conclusions}

In this paper, we compared surface temperatures measured onsite and via ASTER images during both the day and the night to validate the accuracy of surface temperature satellite imagery used frequently in UHI studies. The results indicated that surface temperatures from field measurements were higher than those derived from satellite images during the day, while the opposite pattern was observed during the night, except for in a few locations. Despite the influence of clouds on the images from July 28, the temperature difference between ASTER images and field measurements was smaller during the night than during the day. While surface temperature differences were small for pixels containing trees and grass during the day, at night the artificial fabrics showed a lesser difference. 


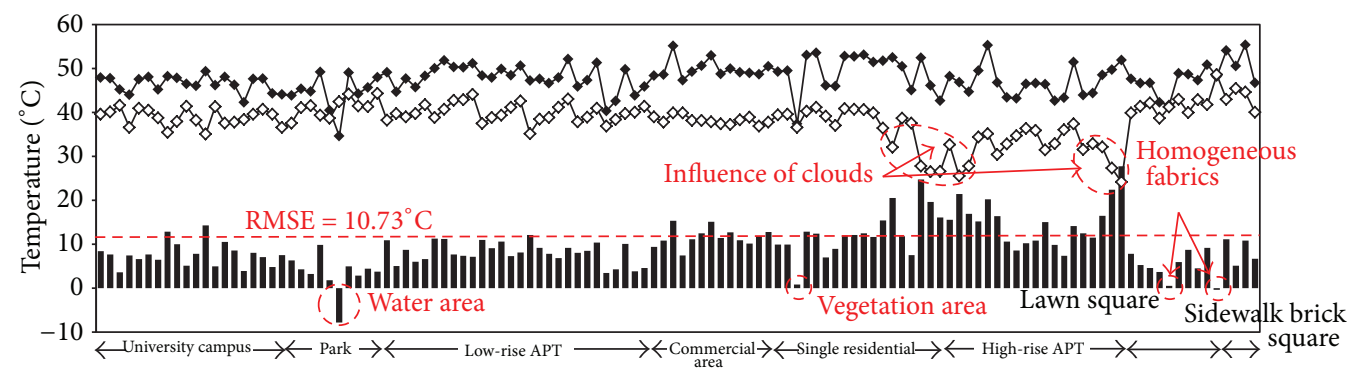

(a)

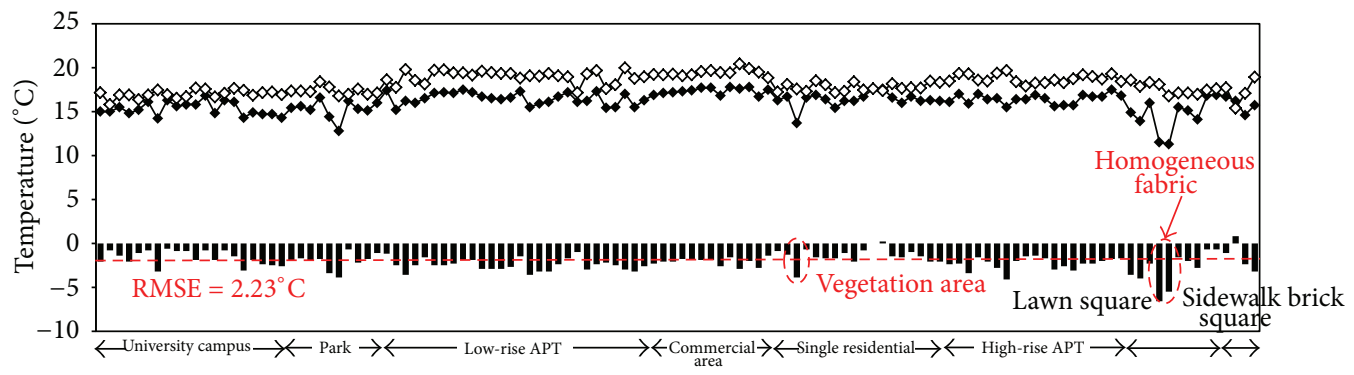

(b)

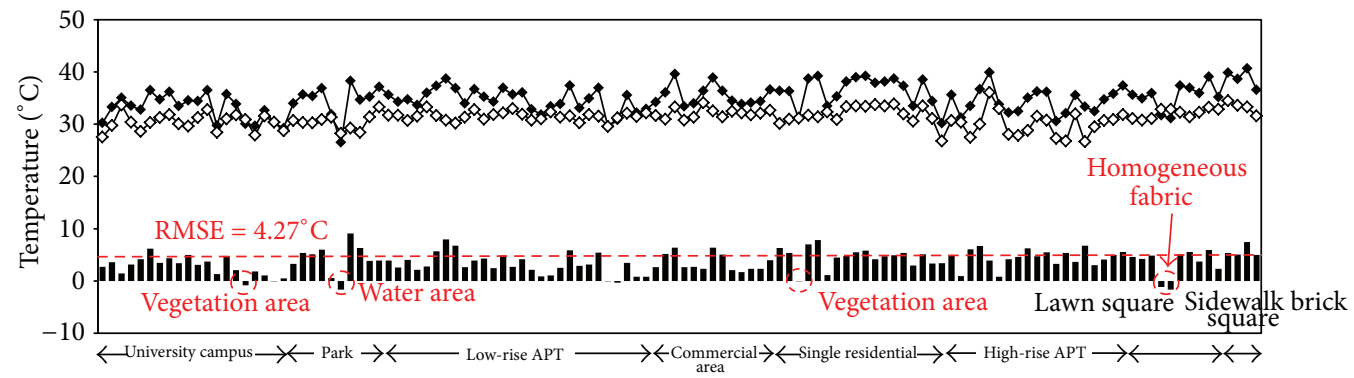

(c)

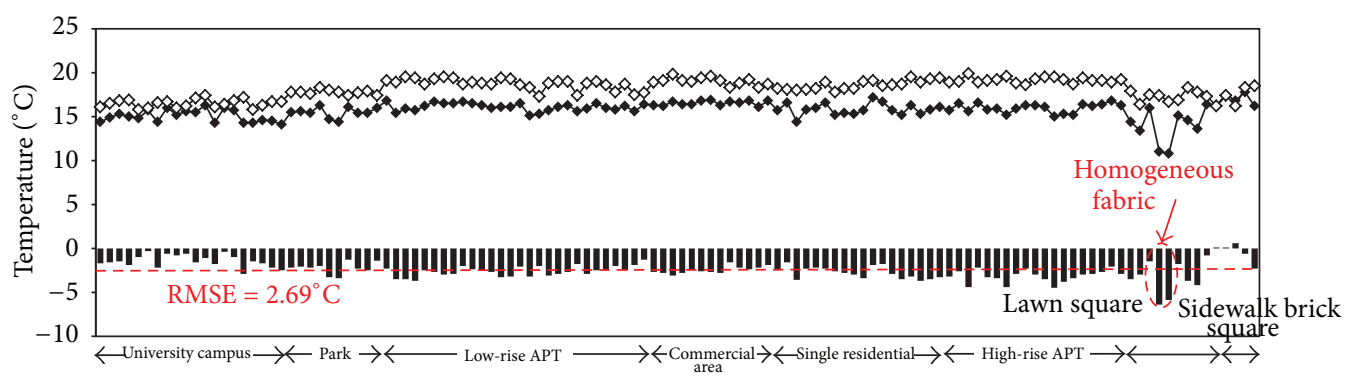

(d)

FIGURE 7: Analysis results for pixel-based surface temperatures collected by ASTER images and field measurements. (a) 07/28, (b) 09/21, (c) 09/23, and (d) 09/28 ( $\diamond$ : ASTER images, $\diamond$ : field measurements, $\mathbf{n}$ : field measurements, ASTER images, and dashed lines: RMSE).

This study confirmed problems with the accuracy of surface temperature data derived from satellite images, and these problems vary according to the time of day and the presence of different urban area characteristics. In particular, areas of high density displayed greater discrepancies in temperature compared to open areas. The difference in temperature between field-based and satellite-based measurements was also affected by whether the surface fabric was artificial or not. Overall, differences between infrared satellite image surface temperature data and onsite measurements may be caused by the off-nadir angle of the satellite image, the limited horizontal surface view of earth's surface, the low spatial resolution of the satellite image, and the application of emissivity values that do not consider the complex spatial characteristics of urban areas. To improve the accuracy of surface temperatures extracted from infrared satellite imagery, we propose a revised model whereby temperature data is obtained from ASTER and emissivity values for various land covers that are extracted based on in situ measurements. 
In the future, we will aim to use the data collected in this study to develop a way to improve the accuracy of satellite derived surface temperature data in urban areas. Also, we plan on further assessing the relationship between radiant energy and surface temperatures according to variations in the spatial characteristics of urban areas. Such studies may help to improve the usability of satellite image data in urban areas and likely will also aid urban planners, developers, and researchers in mitigating the adverse effects of heat islands.

\section{Conflict of Interests}

The authors declare that there is no conflict of interests regarding the publication of this paper.

\section{Acknowledgments}

This research was supported by Korea Aerospace Research Institute (KARI) (no. 2012-0091-0000) and Basic Science Research Program through the National Research Foundation of Korea (NRF) funded by the Ministry of Education, Science and Technology (no. 2013-0095-0000).

\section{References}

[1] T. R. Oke, Boundary Layer Climates, Methuen, London, UK, 2nd edition, 1987.

[2] I. Eliasson, "Urban nocturnal temperatures, street geometry and land use," Atmospheric Environment, vol. 30, no. 3, pp. 379392,1996

[3] K. G. Lee and W. H. Hong, "A study on the urban heat environment pattern analysis and alleviation plan," The Architectural Institute of Korea, vol. 24, no. 9, 2008.

[4] H. Takebayashi and M. Moriyama, "Study on the urban heat island mitigation effect achieved by converting to grass-covered parking," Solar Energy, vol. 83, no. 8, pp. 1211-1223, 2009.

[5] S. L. Harlan, A. J. Brazel, L. Prashad, W. L. Stefanov, and L. Larsen, "Neighborhood microclimates and vulnerability to heat stress," Social Science and Medicine, vol. 63, no. 11, pp. 28472863, 2006.

[6] R. S. Kovats and S. Hajat, "Heat stress and public health: a critical review," Annual Review of Public Health, vol. 29, pp. 4155, 2008.

[7] R. Lafortezza, G. Carrus, G. Sanesi, and C. Davies, "Benefits and well-being perceived by people visiting green spaces in periods of heat stress," Urban Forestry and Urban Greening, vol. 8, no. 2, pp. 97-108, 2009.

[8] E. Ng, L. Chen, Y. Wang, and C. Yuan, "A study on the cooling effects of greening in a high-density city: an experience from Hong Kong," Building and Environment, vol. 47, no. 1, pp. 256271, 2012.

[9] S. H. Baek, A. Shimizu, H. Y. Kim, and E. H. Jung, "Evaluation of thermal environment improvement effect from public design improvement project on the urban street space," Journal of the Environmental Sciences, vol. 20, no. 9, pp. 1105-1114, 2011.

[10] E. L. Krüger, F. O. Minella, and F. Rasia, "Impact of urban geometry on outdoor thermal comfort and air quality from field measurements in Curitiba, Brazil," Building and Environment, vol. 46, no. 3, pp. 621-634, 2011.
[11] S. Knapp, I. Kühn, O. Schweiger, and S. Klotz, "Challenging urban species diversity: contrasting phylogenetic patterns across plant functional groups in Germany," Ecology Letters, vol. 11, no. 10, pp. 1054-1064, 2008.

[12] G. Luber and M. McGeehin, "Climate change and extreme heat events," American Journal of Preventive Medicine, vol. 35, no. 5, pp. 429-435, 2008.

[13] D. E. Bowler, L. Buyung-Ali, T. M. Knight, and A. S. Pullin, "Urban greening to cool towns and cities: a systematic review of the empirical evidence," Landscape and Urban Planning, vol. 97, no. 3, pp. 147-155, 2010.

[14] B. G. Song and K. H. Park, "The classification of spatial patterns considering formation parameters of urban climate: the case of Changwon city, South Korea," Journal of Environmental Impact Assessment, vol. 20, no. 3, pp. 299-311, 2011.

[15] D. A. Quattrochi and J. C. Luvall, “Thermal infrared remote sensing for analysis of landscape ecological processes: methods and applications," Landscape Ecology, vol. 14, no. 6, pp. 577-598, 1999.

[16] J. A. Voogt and T. R. Oke, "Thermal remote sensing of urban climates," Remote Sensing of Environment, vol. 86, no. 3, pp. 370384, 2003.

[17] Q. Weng, D. Lu, and J. Schubring, "Estimation of land surface temperature-vegetation abundance relationship for urban heat island studies," Remote Sensing of Environment, vol. 89, no. 4, pp. 467-483, 2004.

[18] L. Klok, S. Zwart, H. Verhagen, and E. Mauri, "The surface heat island of Rotterdam and its relationship with urban surface characteristics," Resources, Conservation and Recycling, vol. 64, pp. 23-29, 2012.

[19] J. E. Nichol, "A GIS-based approach to microclimate monitoring in Singapore's high-rise housing estates," Photogrammetric Engineering \& Remote Sensing, vol. 60, no. 10, pp. 1225-1232, 1994.

[20] J. A. Voogt and T. R. Oke, "Effects of urban surface geometry on remotely-sensed surface temperature," International Journal of Remote Sensing, vol. 19, no. 5, pp. 895-920, 1998.

[21] Q. Weng, H. Liu, and D. Lu, "Assessing the effects of land use and land cover patterns on thermal conditions using landscape metrics in city of Indianapolis, United States," Urban Ecosystems, vol. 10, no. 2, pp. 203-219, 2007.

[22] H. Liu and Q. Weng, "Seasonal variations in the relationship between landscape pattern and land surface temperature in Indianapolis, USA," Environmental Monitoring and Assessment, vol. 144, no. 1-3, pp. 199-219, 2008.

[23] Q. Weng and D. Lu, "A sub-pixel analysis of urbanization effect on land surface temperature and its interplay with impervious surface and vegetation coverage in Indianapolis, United States," International Journal of Applied Earth Observation and Geoinformation, vol. 10, no. 1, pp. 68-83, 2008.

[24] T. N. Carlson, J. K. Dodd, S. G. Benjamin, and J. N. Cooper, "Satellite estimation of the surface energy balance, moisture availability and thermal inertia," Journal of Applied Meteorology, vol. 20, no. 1, pp. 67-87, 1981.

[25] X. Zhang, Y. Aono, and N. Monji, "Spatial variability of urban surface heat fluxes estimated from Landsat TM data under summer and winter conditions," Journal of Agricultural Meteorology, vol. 54, no. 1, pp. 1-11, 1998.

[26] S. Kato and Y. Yamaguchi, "Analysis of urban heat-island effect using ASTER and ETM+ Data: separation of anthropogenic heat discharge and natural heat radiation from sensible heat flux," Remote Sensing of Environment, vol. 99, no. 1-2, pp. 4454, 2005. 
[27] A. Buyantuyev and J. Wu, "Urban heat islands and landscape heterogeneity: linking spatiotemporal variations in surface temperatures to land-cover and socioeconomic patterns," Landscape Ecology, vol. 25, no. 1, pp. 17-33, 2010.

[28] J. Li, C. Song, L. Cao, F. Zhu, X. Meng, and J. Wu, "Impacts of landscape structure on surface urban heat islands: a case study of Shanghai, China," Remote Sensing of Environment, vol. 115, no. 12, pp. 3249-3263, 2011.

[29] G. Fu, Z. Shen, P. Shi, Y. Zhang, and J. Wu, "Estimating air temperature of an alpine meadow on the Northern Tibetan Plateau using MODIS land surface temperature," Acta Ecologica Sinica, vol. 31, pp. 8-13, 2011.

[30] A. Benali, A. C. Carvalho, J. P. Nunes, N. Carvalhasis, and A. Santos, "Estimating air temperature in Portugal using MODIS LST data," Remote Sensing of Environment, vol. 124, pp. 108-121, 2012.

[31] A. Chudnovsky, E. Ben-Dor, and H. Saaroni, "Diurnal thermal behavior of selected urban objects using remote sensing measurements," Energy and Buildings, vol. 36, no. 11, pp. 1063-1074, 2004.

[32] Q. Weng, "Thermal infrared remote sensing for urban climate and environmental studies: methods, applications, and trends," ISPRS Journal of Photogrammetry and Remote Sensing, vol. 64, no. 4, pp. 335-344, 2009.

[33] C. Mihalcea, B. W. Brock, G. Diolaiuti et al., "Using ASTER satellite and ground-based surface temperature measurements to derive supraglacial debris cover and thickness patterns on Miage Glacier (Mont Blanc Massif, Italy)," Cold Regions Science and Technology, vol. 52, no. 3, pp. 341-354, 2008.

[34] G. Rigo, E. Parlow, and D. Oesch, "Validation of satellite observed thermal emission with in-situ measurements over an urban surface," Remote Sensing of Environment, vol. 104, no. 2, pp. 201-210, 2006.

[35] J. E. Nichol, W. Y. Fung, K.-S. Lam, and M. S. Wong, "Urban heat island diagnosis using ASTER satellite images and 'in situ' air temperature," Atmospheric Research, vol. 94, no. 2, pp. 276284, 2009.

[36] D. A. Hartz, L. Prashad, B. C. Hedquist, J. Golden, and A. J. Brazel, "Linking satellite images and hand-held infrared thermography to observed neighborhood climate conditions," Remote Sensing of Environment, vol. 104, no. 2, pp. 190-200, 2006.

[37] Changwon city hall homepage, http://www.changwon.or.kr.

[38] B. G. Song and K. H. Park, "An analysis of cold air generation area considering climate-ecological function-focus on Chagnwon-si, Gyeongsangnam-do," Journal of the Korean Association of Geographic Information Studies, vol. 13, no. 1, pp. 114$127,2010$.

[39] S. Kato and Y. Yamaguchi, "Estimation of storage heat flux in an urban area using ASTER data," Remote Sensing of Environment, vol. 110, no. 1, pp. 1-17, 2007.

[40] A. R. Gillespie, S. Rokugawa, S. J. Hook, T. Mansunaga, and A. B. Kahle, "Temperature/Emissivity Separation Algorithm Theoretical Basis Document, Version 2.4," NASA contract NAS5-31372, Washington, DC, USA, 1999.

[41] Changwon-si, "The construction of Changwon-si environmental atlas and GIS DB (1st)," Changwon-si Research Report, Changwon, Republic of Korea, 2009.

[42] S. Kato, T. Matsunaga, and Y. Yamaguchi, "Influence of shade on surface temperature in an urban estimated by ASTER data," International Archives of the Photogrammetry, Remote Sensing and Spatial Information Science, vol. 38, pp. 925-929, 2010.
[43] K.-S. Cheng, Y.-F. Su, F.-T. Kuo, W.-C. Hung, and J.-L. Chiang, "Assessing the effect of landcover changes on air temperatu $\times$ re using remote sensing images-A pilot study in northern Taiwan," Landscape and Urban Planning, vol. 85, no. 2, pp. 85-96, 2008.

[44] D. E. Sabol Jr., A. R. Gillespie, E. Abbott, and G. Yamada, "Field validation of the ASTER Temperature-Emissivity Separation algorithm," Remote Sensing of Environment, vol. 113, no. 11, pp. 2328-2344, 2009.

[45] J. A. Sobrino, R. Oltra-Carrió, J. C. Jiménez-Muñoz et al., "Emissivity mapping over urban areas using a classificationbased approach: application to the Dual-use European Security IR Experiment (DESIREX)," International Journal of Applied Earth Observation and Geoinformation, vol. 18, pp. 141-147, 2012.

[46] E. Valor and V. Caselles, "Mapping land surface emissivity from NDVI: application to European, African, and South American areas," Remote Sensing of Environment, vol. 57, no. 3, pp. 167-184, 1996.

[47] V. Caselles, C. Coll, E. Valor, and E. Rubio, "Mapping land surface emissivity using AVHRR data application to La Mancha, Spain," Remote Sensing Reviews, vol. 12, no. 3-4, pp. 311-333, 1995.

[48] S. P. Arya, Introduction to Micrometeorology, Academic Press, 2nd edition, 2003.

[49] B. G. Song, Development of integrated spatial environmental assessment and planning methods for improving the urban climate and air quality [M.S. thesis], Changwon National University, Changwon, Republic of Korea, 2011.

[50] E. Erell, D. Pearlmutter, and T. Williamson, Urban Microclimate: Designing the Spaces Between Buildings, Earthscan, Washington, DC, USA, 2012.

[51] L. Barring, J. O. Mattsson, and S. Lindqvist, "Canyon geometry, street temperatures and urban heat island in Malmo, Sweden," Journal of Climatology, vol. 5, no. 4, pp. 433-444, 1985.

[52] K.-S. Han, A. A. Viau, and F. Anctil, "An analysis of GOES and NOAA derived land surface temperatures estimated over a boreal forest," International Journal of Remote Sensing, vol. 25, no. 21, pp. 4761-4780, 2004. 

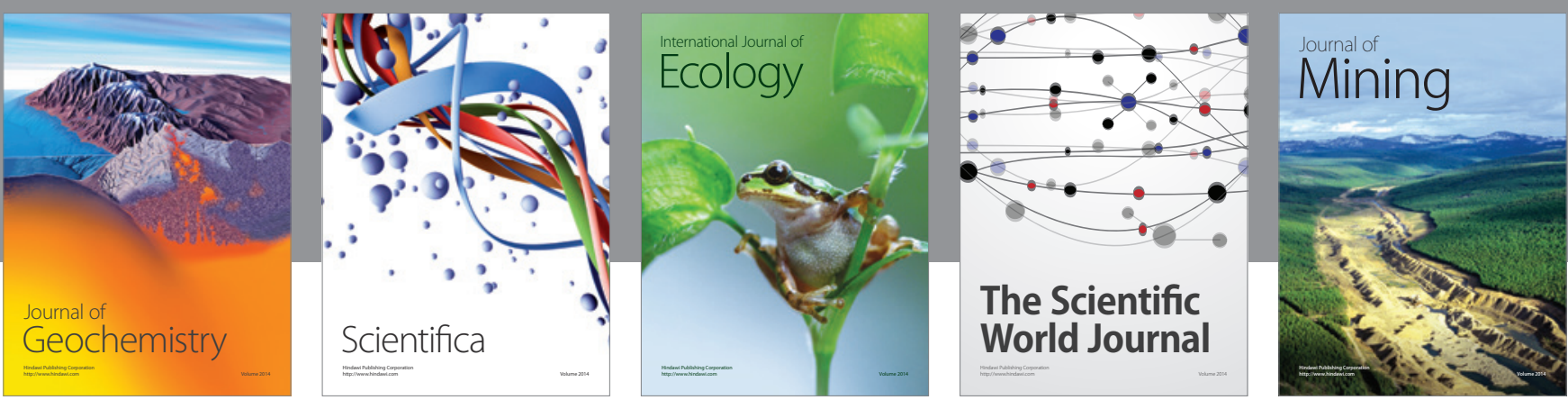

The Scientific World Journal
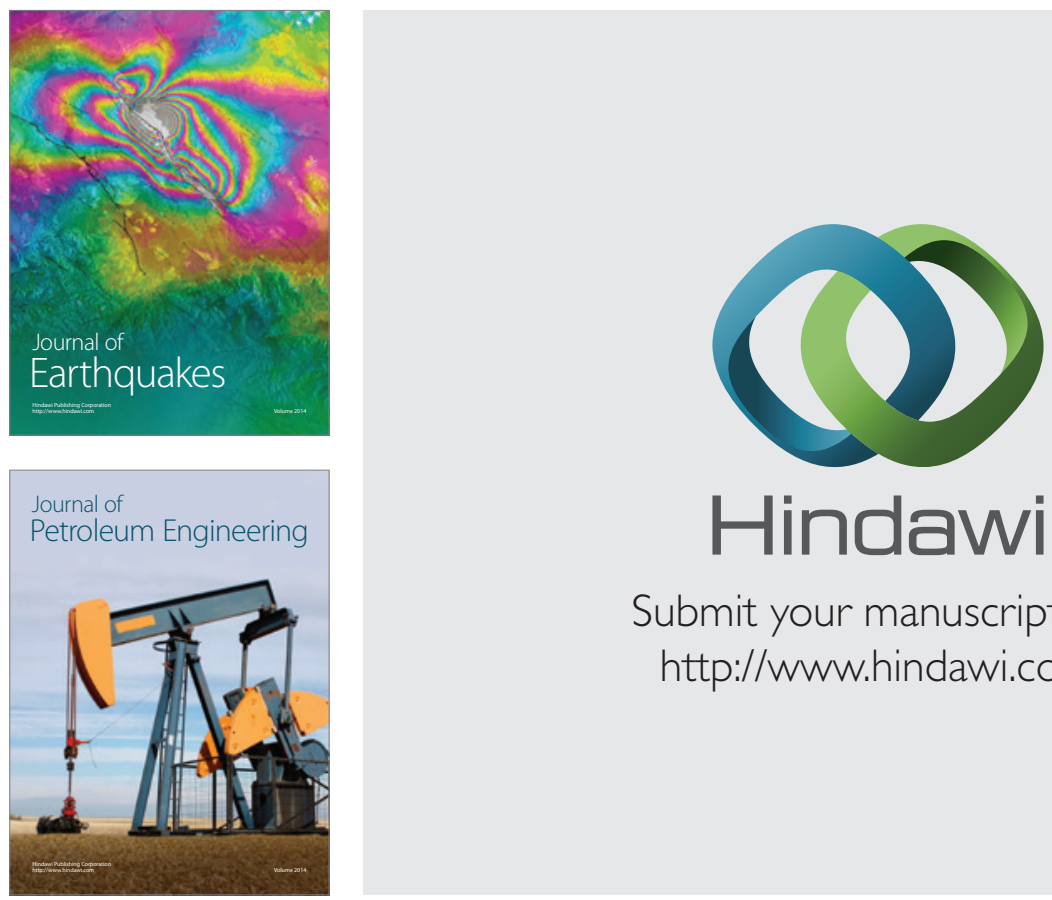

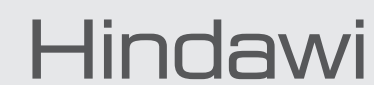

Submit your manuscripts at

http://www.hindawi.com
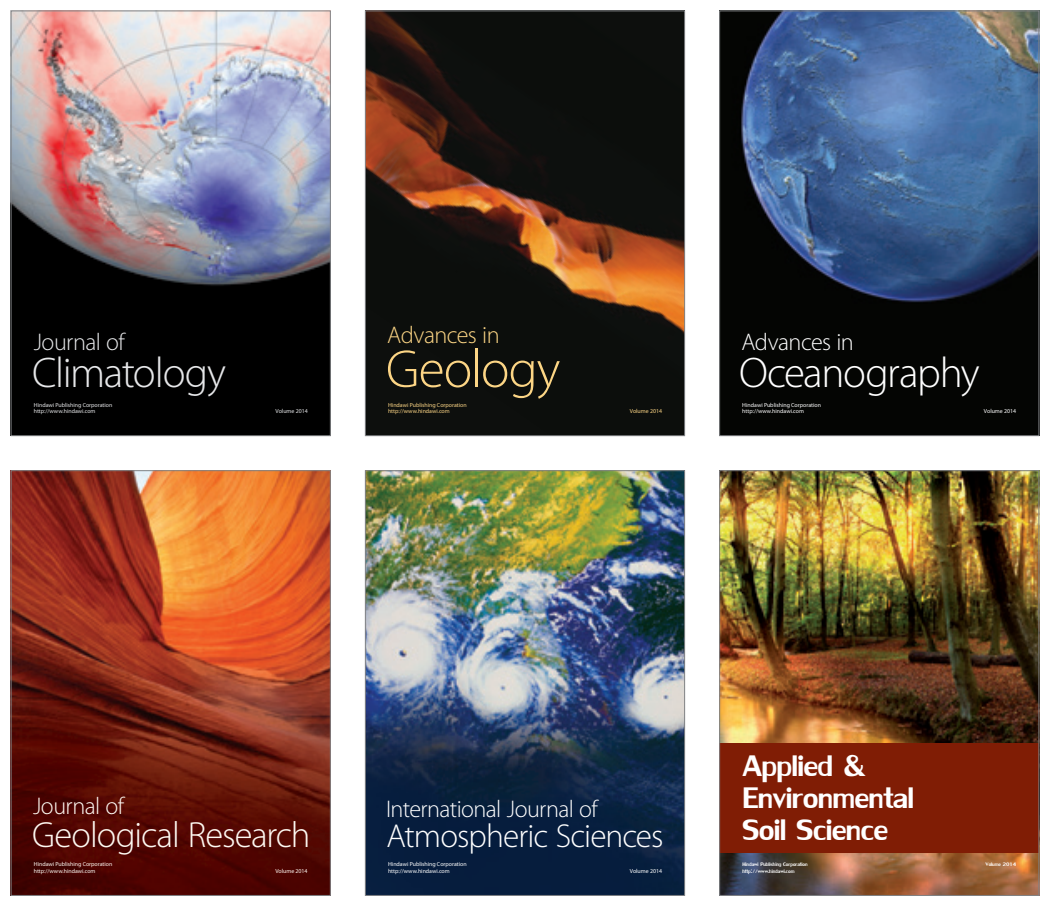
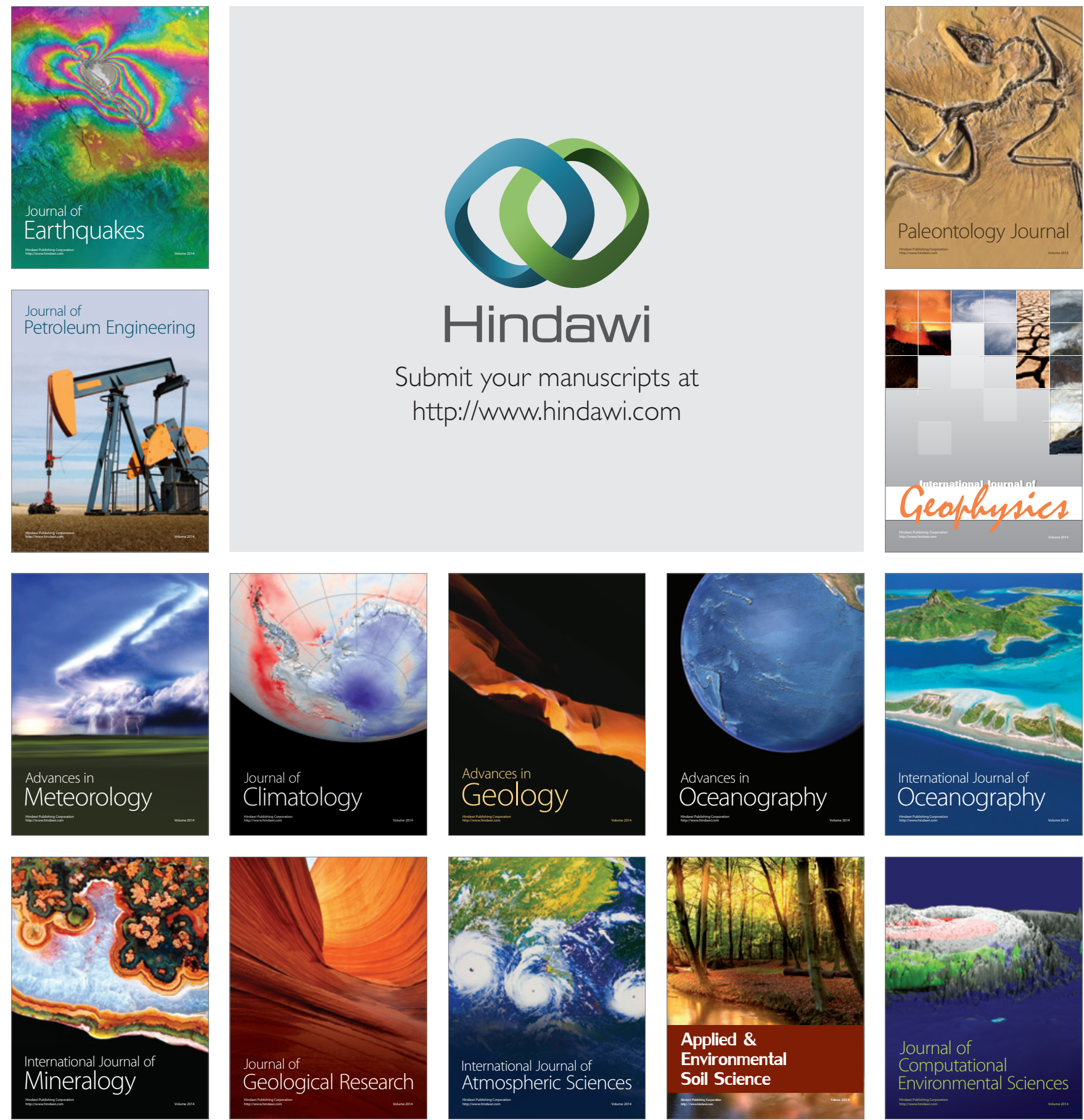